Published in: J. Nucl. Mater., http://dx.doi.org/10.1016/j.jnucmat.2016.04.052

\title{
Experimental determination of the deuterium binding energy with vacancies in tungsten
}

\author{
M. Zibrov ${ }^{\text {a,b,c }}$, S. Ryabtsev ${ }^{\mathrm{a}}$, Yu. Gasparyan ${ }^{\mathrm{a}}$, A. Pisarev $^{\mathrm{a}}$ \\ ${ }^{a}$ National Research Nuclear University MEPhI (Moscow Engineering Physics Institute), Kashirskoe \\ shosse 31, 115409 Moscow, Russia \\ ${ }^{b}$ Max-Planck-Institut für Plasmaphysik, Boltzmannstraße 2, D-85748 Garching, Germany \\ ${ }^{c}$ Gent University, Sint-Pietersnieuwstraat 41, B-9000 Gent, Belgium
}

\begin{abstract}
Deuterium (D) interaction with vacancies in tungsten (W) was studied using thermal desorption spectroscopy (TDS). In order to obtain a TDS spectrum with a prominent peak corresponding to $\mathrm{D}$ release from vacancies, a special procedure comprising damaging of a recrystallized $\mathrm{W}$ sample by low fluences of $10 \mathrm{keV} / \mathrm{D}$ ions, its annealing, and subsequent lowenergy ion implantation, was utilized. This experimental sequence was performed several times in series; the only difference was the TDS heating rate that varied in the range of $0.15-4 \mathrm{~K} / \mathrm{s}$. The sum of the D binding energy $\left(E_{b}\right)$ with vacancies and the activation energy for D diffusion $\left(E_{D}\right)$ in $\mathrm{W}$ was then directly determined from the slope of the Arrhenius-like plot $\ln \left(\beta / T_{m}^{2}\right)$ versus $1 / T_{m}$, where $\beta$ - heating rate and $T_{m}$ - position of the respective peak in the TDS spectrum. The determined value of $E_{\mathrm{b}}+E_{D}$ was $1.56 \pm 0.06 \mathrm{eV}$.
\end{abstract}

Keywords: tungsten, deuterium, thermal desorption, binding energy, vacancies, radiation defects; E-mail: Mikhail.Zibrov@ipp.mpg.de. Tel.: +49 893299 1919; fax: +49 8932992279. 


\section{Introduction}

Tungsten (W) will be used as a plasma-facing material in the divertor region in ITER, and its use in future fusion devices is currently likely. Due to a very low solubility of hydrogen $(\mathrm{H})$ isotopes in $\mathrm{W}$, the presence of various lattice defects (vacancies, vacancy clusters, voids, dislocations, grain boundaries, impurities) strongly influences $\mathrm{H}$ isotope retention in $\mathrm{W}$ [1]. Therefore parameters of trapping, particularly hydrogen trapping/detrapping energies and detrapping attempt frequencies, are essential for predicting $\mathrm{H}$ isotope transport and retention in W plasma-facing components. So far, however, there is no general agreement about these values. For instance, the value of the detrapping energy for the first trapped $\mathrm{H}$ atom in a single vacancy in $\mathrm{W}$ varies among researchers in the wide range of 1.29-1.79 eV [2-11].

Calculations of the hydrogen-defect interaction are often performed by using the density functional theory (DFT) [5-11]. Experimental investigations of the hydrogen-defect interaction are often performed by thermal desorption spectroscopy (TDS), and the parameters of the interaction are obtained by fitting numerical calculations based on diffusion-trapping codes to experimental thermal desorption spectra [3, 4, 12-17]. Aside from the uncertainties of the thermal desorption measurements [18, 19], a large uncertainty in the determination of characteristics of trapping sites in this approach is given by the fact that a result of a TDS spectrum simulation depends on many input parameters in the numerical model $(\mathrm{H}$ detrapping energy, $\mathrm{H}$ diffusivity in the material, trap concentration profile, initial distribution of trapped $\mathrm{H}$, recombination rate at the surface). As a result, one experimental spectrum can be fitted by using

many combinations of fitting parameters [4]. However, under the condition of a high $\mathrm{H}-\mathrm{H}$ recombination rate at the surface, the $\mathrm{H}$ binding energy with a defect can be directly determined from the shift of the desorption maximum in a series of TDS measurements performed with identical samples but with different heating rates [20, 21]. 
The most common problem of TDS experiments is the interpretation of the types of defects responsible for particular peaks. Therefore it is essential to investigate samples having only one dominant and well-known defect type. In the case of irradiation of metals by light ions with energies in the keV range, mainly point defects (Frenkel pairs - single vacancies and interstitial atoms) are formed as the energy transfer from an incident ion to a metal atom is relatively low; thus, dense collision cascades are not formed [22]. At low irradiation fluences (corresponding to low damage levels), the concentration of created vacancies is small; therefore, at the temperatures when their mobility is low, the fraction of vacancy clusters is small [3, 23, 24].

In the present contribution, this approach is used for direct determination of the deuterium (D) binding energy with single vacancies in W from TDS measurements with different heating rates.

\section{Theory}

The energy state of a $\mathrm{H}$ atom near a trapping site is schematically shown in Fig. 1. Here, by the binding energy $E_{b}$ we denote the difference in the potential energy of a $\mathrm{H}$ atom in a trap and in a solution site. By the activation energy for trapping $E_{t r}$ we mean the energy barrier for a $\mathrm{H}$ atom to enter a trap. By the detrapping energy $E_{d t}$ we mean the energy barrier for $\mathrm{H}$ escape from a trap, which is defined as $E_{d t}=E_{b}+E_{t r}$. In the particular case when the activation energy for trapping $E_{t r}$ is equal to the activation energy for $\mathrm{H}$ diffusion $E_{D}$, the sum $E_{b}+E_{D}$ is equal to the detrapping energy $E_{d t}$. The activation energy for trapping in Fig. $\mathbf{1}$ is shown to be less than the activation energy for diffusion $E_{t r}<E_{D}$, but the opposite case of $E_{t r} \geq E_{D}$ is also possible.

As the surface effects can retard hydrogen release and thus complicate TDS analyses, we will assume and consider only the case of a very fast $\mathrm{H}-\mathrm{H}$ recombination at the surface, so that the surface effects do not influence both the TDS peak position and its shape. In this case two limiting $\mathrm{H}$ release regimes were identified: detrapping-limited regime and retrapping-limited 
regime [20]. In the former case, the concentration of traps $N_{t}$ (in atomic fractions) is so low $\left(N_{t}<<\left(\frac{\lambda}{\Delta}\right)^{2}\right.$, where $\lambda$ - lattice constant, $\Delta$ - characteristic location depth of trapped $\mathrm{H}$ ) that a $\mathrm{H}$ atom after release from a trap diffuses to the surface without being retrapped by other traps. In the latter case, the concentration of traps is high enough $\left(N_{t}>>\left(\frac{\lambda}{\Delta}\right)^{2}\right)$, so a $\mathrm{H}$ atom released from a trap can be retrapped many times by empty traps before reaching the surface.

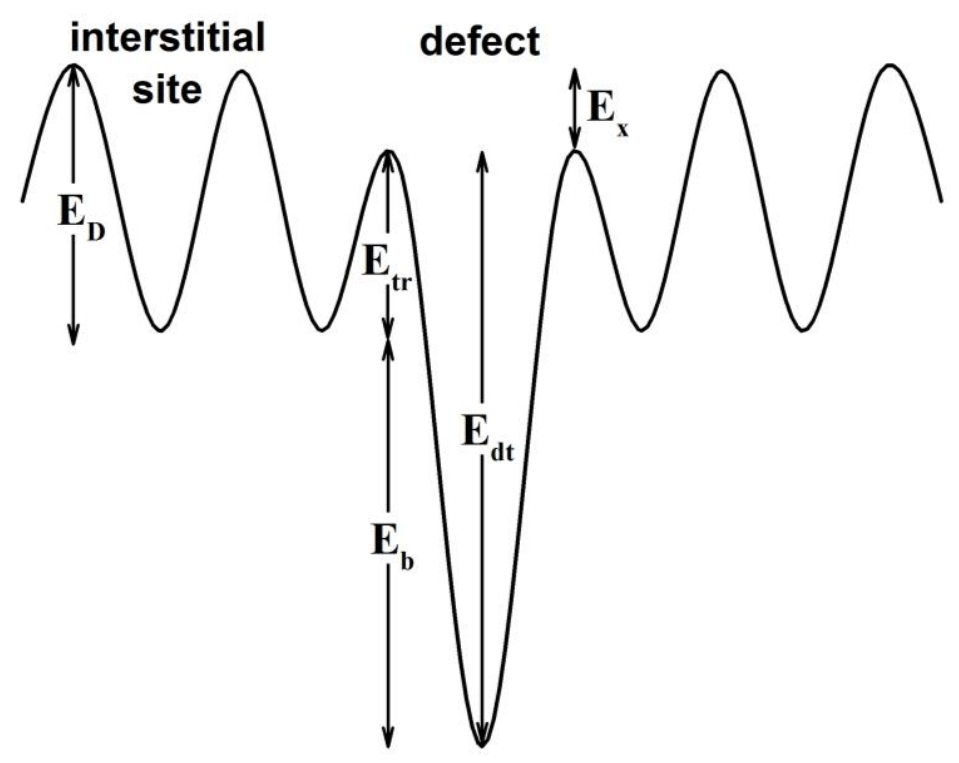

Fig. 1. Potential energy diagram for a $\mathrm{H}$ atom near a defect in a metal, where $E_{d t}-$ the detrapping energy, $E_{b}$ - the binding energy, $E_{t r}-$ the activation energy for trapping, $E_{D}-$ the activation energy for diffusion, and $E_{x}$ - the difference between the activation energy for trapping and the activation energy for diffusion.

In the case of the detrapping-limited regime the relation between the $\mathrm{H}$ detrapping energy $E_{d t}$ from a defect, the heating rate $\beta$ during TDS, and the respective peak position $T_{m}$ in a TDS spectrum, is expressed in the following way [20]: 


$$
\ln \left(\frac{\beta}{T_{\mathrm{m}}^{2}}\right)=\ln \left(v_{d t} \frac{k}{E_{d t}}\right)-\frac{E_{d t}}{k} \frac{1}{T_{\mathrm{m}}}
$$

where $v_{d t}$ - the detrapping attempt frequency, $k$ - Boltzmann constant.

In the case of the retrapping-limited regime, the equation is the same, but the sum $E_{\mathrm{b}}+E_{\mathrm{D}}$ appear instead of $E_{d t}$ :

$$
\ln \left(\frac{\beta}{T_{\mathrm{m}}^{2}}\right)=\ln \left(v_{e f f} \frac{k}{E_{b}+E_{D}}\right)-\frac{E_{b}+E_{D}}{k} \frac{1}{T_{\mathrm{m}}},
$$

where $v_{\text {eff }}-$ the effective detrapping attempt frequency, which depends both on the properties of the trapping sites and of the bulk.

Thus, depending on the release regime, either the detrapping energy $E_{d t}$ or the sum $E_{\mathrm{b}}+E_{\mathrm{D}}$ can be directly determined from the slope of the Arrhenius-like plot $\ln \left(\beta / T_{m}^{2}\right)$ versus $1 / T_{m}$ in a series of TDS measurements performed using identical samples and different heating rates (the so-called Kissinger method [25]). One should note that in this approach no prior knowledge of the trap profile, the initial distribution of trapped hydrogen, and the material properties is required - the only requirement is a sufficiently high recombination rate at the surface [21]. In addition, this method allows to determine either $E_{d t}$ or $E_{\mathrm{b}}+E_{\mathrm{D}}$ independently of the detrapping attempt frequency $v_{d t}$, while this is not possible in fitting of numerically simulated TDS spectra to experimental ones where the value of $v_{d t}$ has to be assumed (typically assumed to be of the same order of magnitude as the lattice vibration frequency, i.e. $\sim 10^{13} \mathrm{~s}^{-1}$ ).

Although all the considerations described above were made for a metal containing only one type of trapping sites (characterised by the values of $E_{b}$ and $E_{t r}$ ) and each trap can accommodate only one $\mathrm{H}$ atom, the same dependences are valid for every trap type in the metal as long as they do not evolve during the TDS measurements. The same dependencies should be also valid in the 
case of trapping of several $\mathrm{H}$ atoms by each trap since it can be approximated by several distinct trapping sites [20]. From the experimental point of view, in the case of a material with several types of trapping sites, TDS peaks must be well-resolved to determine their positions accurately.

\section{Experimental details}

\subsection{Experimental setup}

The experiments were carried out in the MEDION ion-beam facility (MEPhI, Moscow) [26]. An ion beam is extracted from a duoplasmatron ion source, passes through an einzel lens, is mass-separated in a $60^{\circ}$ deflection magnet, and then directed onto a sample. The rather broad beam is restricted by a $3 \mathrm{~mm}$ diaphragm at the entrance of the target chamber. The measurement of the ion current on the sample during irradiation is performed without suppression of the secondary electron emission. Real ion currents are controlled in independent measurements using a Faraday cup with a negatively biased electron-suppressor lid.

The target chamber is separated from the ion source by several differential pumping stages and has a base pressure below $5 \times 10^{-7} \mathrm{~Pa}$ with mass $2\left(\mathrm{H}_{2}\right)$ as the main component; the contributions of masses $18\left(\mathrm{H}_{2} \mathrm{O}\right)$ and $28(\mathrm{CO})$ are more than one order of magnitude less. During ion implantation, the pressure increases to about $10^{-6} \mathrm{~Pa}$ mainly due to leaking of $\mathrm{D}_{2}$ gas from the ion source. A quadrupole mass-spectrometer (QMS) is installed in the target chamber, which allows in situ TDS analysis. The QMS is located not in the line-of-sight of the sample, thus, only the rise of the partial pressures of monitored gases (ten masses) is measured by the QMS during TDS. The QMS signal for mass $4\left(\mathrm{D}_{2}\right.$ and $\left.\mathrm{He}\right)$ is calibrated by using a helium leak. The relative QMS sensitivities for $\mathrm{D}_{2}$ and $\mathrm{He}$, as well as for masses 3 (HD) and 4 were determined by using procedures described in [27]. 
The sample in the shape of a thin strip $\left(15 \times 50 \mathrm{~mm}^{2}\right)$ is mounted on two water-cooled electrical feedthroughs and can be resistively heated by DC current. Only a small central part ( $3 \mathrm{~mm}$ in diameter) of the sample is subjected to irradiation to minimize the influence of nonuniformity of the temperature over the sample surface during TDS. The sample temperature near the beam strike area is measured by a spot-welded tungsten-rhenium thermocouple. The error in the temperature measurement induced by a current passing through the sample is $\sim 1 \mathrm{~K}$ at the temperatures of interest $(<900 \mathrm{~K})$. The linearity of the sample heating during TDS is controlled by a loop feedback system based on a proportional-integral-derivative (PID) control.

\subsection{The sample}

The sample was cut from a $25 \mu \mathrm{m}$ thick hot-rolled polycrystalline $\mathrm{W}$ foil with the purity of 99.97 wt.\% produced by Plansee. It was successively cleaned in an ultrasonic bath with gasoline, acetone, and ethanol. In order to minimize the concentration of intrinsic defects in the sample (dislocations, grain boundaries), the sample was annealed at $1800 \mathrm{~K}$ for $30 \mathrm{~min}$; and this led to the full material recrystallization [28]. SEM investigations revealed that the recrystallized sample had isotropic grains with dimensions in the range of 10-25 $\mu \mathrm{m}$. Long preliminary annealing reduced possible influence of repetitive heating procedures during TDS measurements.

\subsection{Experimental conditions}

The first step of the experimental cycle was the production of defects (mainly Frenkel pairs) by irradiation with $10 \mathrm{keV} \mathrm{D}{ }^{+}$ions to the fluence of $3 \times 10^{19} \mathrm{D} / \mathrm{m}^{2}$. Calculations with SDTrimSP [29] using the threshold displacement energy of $90 \mathrm{eV}$ [30] demonstrated that approximately one vacancy per incident ion was produced under the conditions of the experiment. The damage profile was approximately Gaussian with a maximum located at a distance of $23 \mathrm{~nm}$ from the surface, and the corresponding maximum damage level was $6.3 \times 10^{-3} \mathrm{dpa}$ (taking into account the reflection coefficient of the incident ions of 0.27 ). The irradiated sample was then annealed at $550 \mathrm{~K}$ for $5 \mathrm{~min}$. Such conditions were sufficient to remove a substantial part of $\mathrm{D}$ from 
vacancies, but growth of vacancy clusters is not expected, as vacancies in $\mathrm{W}$ are still immobile at $550 \mathrm{~K}[23,24]$. Afterwards, the sample was implanted with $2 \mathrm{keV} \mathrm{D}_{3}^{+}(0.67 \mathrm{keV} / \mathrm{D})$ ions to the fluences in the range of $0.5-6 \times 10^{19} \mathrm{D} / \mathrm{m}^{2}$ in order to fill the created vacancies with $\mathrm{D}$ without producing additional displacement damage. Both damaging and low-energy ion implantation were performed at normal ion incidence, and the sample temperature did not exceed $313 \mathrm{~K}$. The ion flux on the sample was in the range of $3-6 \times 10^{16} \mathrm{D} / \mathrm{m}^{2} \mathrm{~s}$. In $3 \mathrm{~h}$ after $\mathrm{D}$ implantation, when the signals of all monitored masses returned to their initial values before the implantation, TDS measurements were performed. Numerical simulations indicate that this time is large enough to release a substantial part of interstitial $\mathrm{D}$ from the sample in the case of a clean $\mathrm{W}$ surface. According to [31], such experimental procedure allows to obtain a TDS spectrum with a prominent peak corresponding to $\mathrm{D}$ release from single vacancies in $\mathrm{W}$.

The experimental sequence with damaging of the sample with $10 \mathrm{keV} / \mathrm{D}$ ions, annealing at $550 \mathrm{~K}$, and subsequent implantation with $0.67 \mathrm{keV} / \mathrm{D}$ ions to the fluence of $1 \times 10^{19} \mathrm{D} / \mathrm{m}^{2}$ followed by TDS measurements was performed several times in series, and the only difference was in the TDS heating rate. Obviously, the heating rates should be varied in a wide range for accurate determination of detrapping energies. However, at very low heating rates the measurements are limited by a low signal/noise ratio, whereas at sufficiently high heating rates the non-linearity of the heating ramp starts playing a role. Therefore in the present experiments the variation of heating rates was limited to the range of $0.15-4 \mathrm{~K} / \mathrm{s}$. All heating ramps exhibited a good linearity: even at the highest heating rate of $4 \mathrm{~K} / \mathrm{s}$ the heating was nonlinear only until $400 \mathrm{~K}$, i.e. far from the peak of interest, as it will be shown later. At the temperatures above $400 \mathrm{~K}$ the deviation of actual heating rates from the programmed ones was within $3 \%$.

As the same sample was used for all measurements, it was annealed at $1700 \mathrm{~K}$ for $1 \mathrm{~h}$ before every new experimental sequence. Such annealing is effective for elimination of all existing vacancies and vacancy clusters $[23,32]$. Since the implantation fluences were very low, no irreversible material modifications (growth of pores, blister-like structures) are expected [32, 
33]. The fact that there was no accumulation of radiation damage in the sample after its multiple use was checked in the end of the experimental campaign by implanting the annealed sample with $0.67 \mathrm{keV} / \mathrm{D}$ ions to the fluence of $1 \times 10^{19} \mathrm{D} / \mathrm{m}^{2}$ which resulted in appearance of a single low-temperature peak near $400 \mathrm{~K}$ (see Fig. 2 in [31]), which corresponds to the D release from the intrinsic defects.

The measurements presented in this paper were carried out after approximately 20 cycles of irradiation and annealing of the sample, which should result in removal of surface impurities which are expected on the virgin sample. In addition, since all the experiments were carried out in ultra-high vacuum conditions without exposure of the sample to air between implantation and TDS measurements, adsorption of impurities (like oxygen and carbon) on the sample surface was strongly reduced. Consequently, it is assumed that under the present experimental conditions the concentration of impurities on the sample surface was low, thus, the recombination rate was high enough not to affect the TDS spectra (at least for the release temperatures above $550 \mathrm{~K}$, when the delay caused by retrapping by surface sites of $\mathrm{D}$ released from the traps is negligible [3]). Therefore, the above mentioned method of determination of detrapping energies should be applicable in the present case.

Although in the present experiments the damage level was relatively low (maximum $\left.6.3 \times 10^{-3} \mathrm{dpa}\right)$, the maximum concentration of vacancies $\left(\sim 2 \times 10^{-4}\right.$ at. fr. as estimated from the amount of D trapped in the TDS peak corresponding to vacancies) is close to that required for the retrapping-limited regime $\left(N_{t}>>\left(\frac{\lambda}{\Delta}\right)^{2} \approx 3 \times 10^{-5}\right.$ at. fr. with $\lambda=0.316 \mathrm{~nm}$ and $\Delta \approx 60 \mathrm{~nm}$ ). Even though in simulations of TDS spectra it is commonly assumed that the activation energy for trapping $E_{t r}$ is equal to the activation energy for diffusion $E_{D}$, the DFT calculations indicate that $E_{t r}<E_{D}$ for vacancies in $\mathrm{W}[8,11]$. In that case $\left(E_{t r} \leq E_{D}\right)$ numerical calculations using the TMAP7 code [34] indicate that under the present experimental conditions (using the estimated concentration of vacancies and their depth distribution taken from the SDTrimSP calculations) 
the sum $E_{b}+E_{D}$ will be determined from the Arrhenius-like plot $\ln \left(\beta / T_{m}^{2}\right)$ versus $1 / T_{m}$. Therefore it is assumed that in the present experiments the sum $E_{b}+E_{D}$ for vacancies in $\mathrm{W}$ is determined.

\section{Experimental results and discussion}

Fig. 2 shows TDS spectra (heating rate $2 \mathrm{~K} / \mathrm{s}$ ) from the $10 \mathrm{keV} / \mathrm{D}$ damaged samples implanted with different fluences of $0.67 \mathrm{keV} / \mathrm{D}$ ions. All the spectra consist of at least two peaks: around $400 \mathrm{~K}$ and around $600 \mathrm{~K}$. The first rather broad peak near $400 \mathrm{~K}$ is suggested to be composed of several more narrow peaks [26], which can be attributed to the D release from the natural bulk defects (grain boundaries, dislocations) $[13,32]$ and from the adsorption sites on the surface $[3,35]$. It may be also suggested that multiple population of vacancies with $\mathrm{D}$ atoms can give a contribution to the $400 \mathrm{~K}$ peak since the detrapping energy decreases with increasing the number of trapped atoms in a vacancy [5-11]. According to our previous results and the results of other researchers, the second peak $(\sim 600 \mathrm{~K})$ in the spectra corresponds to the D release from radiation defects (presumably vacancies) [3, 31, 36, 37]. It should be noted that, apart from single vacancies, W self-interstitials are also formed during irradiation, which can either disappear on the surface as the ion range is very small or agglomerate to form dislocation loops [33]. However, DFT calculations demonstrate that the D binding energies to these types of defects are lower than that to a single vacancy $[5,38]$, therefore the peak near $600 \mathrm{~K}$ can be attributed to the D release from single vacancies in W. As it has been analysed above, defect production conditions are favourable for production of vacancies.

It is important to mention that most of the DFT studies predict that a single vacancy in W can trap several D atoms, and the binding energies of the first and the second D atom are almost equal, whereas for the third and subsequent atoms they are considerably lower $[5,6,9,11]$. As a result, the $600 \mathrm{~K}$ peak may be in principal composed of two closely located peaks corresponding 
to the release of the first and the second trapped D atom from a vacancy. Consequently, the determined sum $E_{b}+E_{D}$ corresponding to the $600 \mathrm{~K}$ peak may comprise the energies for both the first and the second D atoms in a vacancy.

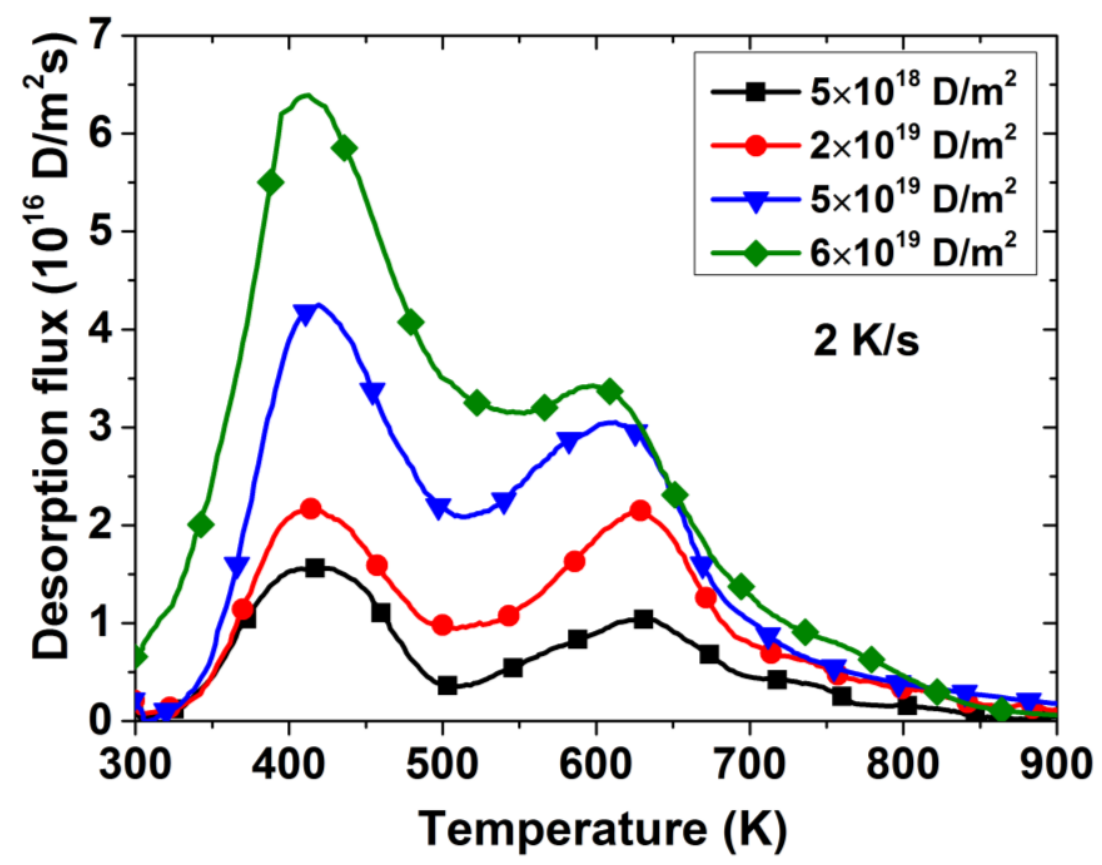

Fig. 2. Thermal desorption spectra of $D_{2}$ molecules from recrystallized $W$ irradiated by $10 \mathrm{keV} / \mathrm{D}$ ions to the fluence of $3 \times 10^{19} \mathrm{D} / \mathrm{m}^{2}$, subsequently annealed at $550 \mathrm{~K}$ for $5 \mathrm{~min}$, and then implanted with $0.67 \mathrm{keV} / \mathrm{D}$ ions to the fluences in the range of $5 \times 10^{18}-6 \times 10^{19} \mathrm{D} / \mathrm{m}^{2}$. The TDS heating rate was $2 \mathrm{~K} / \mathrm{s}$.

Up to the fluence of $5 \times 10^{19} \mathrm{D} / \mathrm{m}^{2}$, the amplitudes of both peaks increased with increasing the fluence. However, at the fluence of $6 \times 10^{19} \mathrm{D} / \mathrm{m}^{2}$, the amplitude of the second peak is only slightly increased with respect to that at the fluence of $5 \times 10^{19} \mathrm{D} / \mathrm{m}^{2}$, whereas the amplitude of the first peak increased significantly. This may indicate that vacancies are almost filled with the first (and probably the second) D atom at the fluences above $5 \times 10^{19} \mathrm{D} / \mathrm{m}^{2}$. In addition, the second peak shifted towards lower temperatures with increasing implantation fluence. This can be attributed to increase of the number of filled vacancies resulting in decrease of $\mathrm{D}$ retrapping 
after release from a vacancy and respectively faster release from the target [4]. In addition, overlapping with a $400 \mathrm{~K}$ peak at high implantation fluences can also result in a peak shift towards lower temperatures.

A small shoulder near $720 \mathrm{~K}$ could be also noted in the spectra, which corresponds to the D release from vacancy clusters, as a relatively small number of them is also formed during the irradiation [23, 32, 39]. Formation of vacancy clusters during the heating and subsequent D retrapping in them during the TDS measurements is also possible. In addition, all the spectra demonstrate the presence of long high-temperature tails extending to $900 \mathrm{~K}$, which were also observed in our previous investigations $[26,32]$. These tails can be either attributed to D release from traps with higher binding energies or to the $\mathrm{D}$ release from the back surface of the specimen or from the non-irradiated parts of the front surface.

As it can be seen from Fig. 2, the second peak gets worse resolved with increasing fluence, which makes the accurate determination of its position difficult. Therefore the fluence of $1 \times 10^{19} \mathrm{D} / \mathrm{m}^{2}$ was chosen for TDS experiments with different heating rates. Obviously, in that case not all the existing vacancies are filled with the first (or the first and the second) D atom. However, TMAP7 simulations indicate that the fraction of traps filled with D has no influence on the experimentally determined value of the sum $E_{\mathrm{b}}+E_{\mathrm{D}}$. In addition, although the presence of the low-temperature peak near $400 \mathrm{~K}$ indicates the existence of additional trapping sites in the material with lower binding energies, numerical simulations indicate that their presence will not affect the determined binding energy, since at the temperatures close to the position of the second peak, these low-energy traps are already weak and almost do not retard the D transport to the surface. The same line of argumentation is valid for the case of trapping of several D atoms by vacancies. Numerical simulations indicate that the presence of a small fraction of trapping sites with higher binding energies (e.g. vacancy clusters) also does not influence the determination of the sum $E_{\mathrm{b}}+E_{\mathrm{D}}$ for vacancies. This is because the high-energy traps are still holding the trapped $\mathrm{D}$ at the temperatures around that of the second peak. 


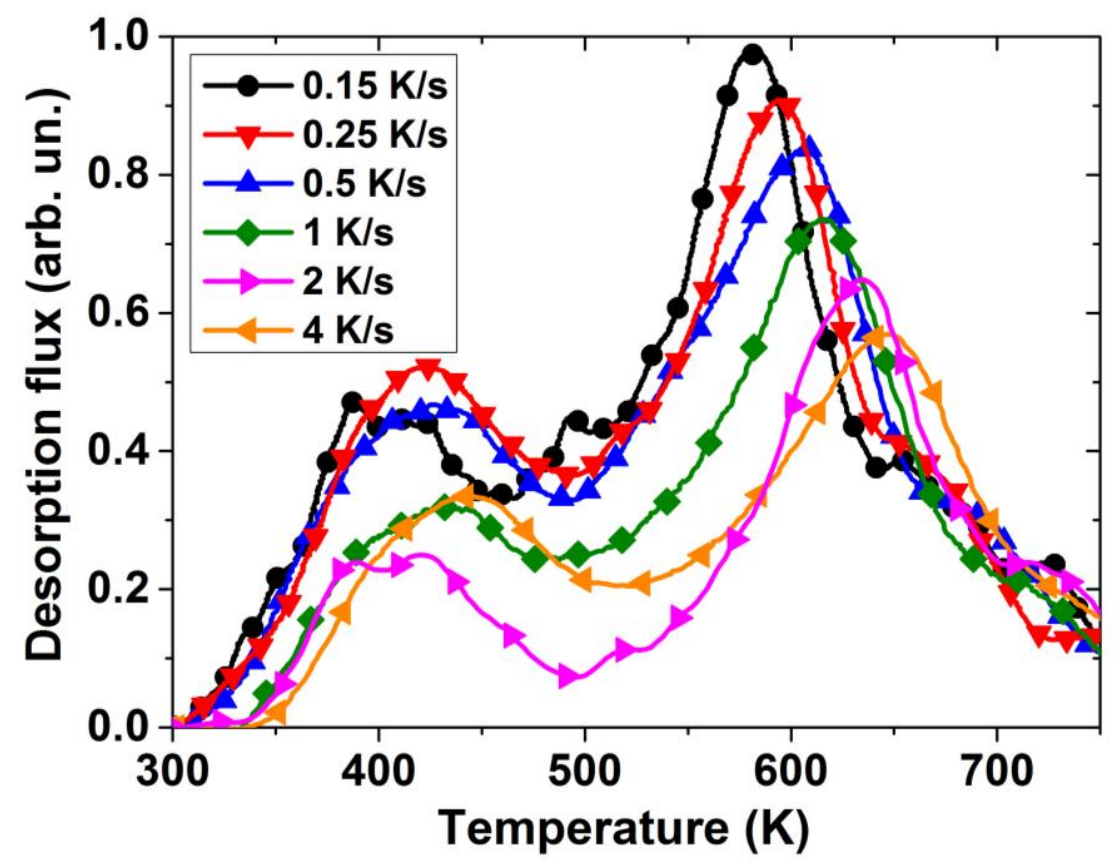

Fig. 3. Thermal desorption spectra of $\mathrm{D}_{2}$ molecules from recrystallized $\mathrm{W}$ irradiated by $10 \mathrm{keV} / \mathrm{D}$ ions to the fluence of $3 \times 10^{19} \mathrm{D} / \mathrm{m}^{2}$, subsequently annealed at $550 \mathrm{~K}$ for $5 \mathrm{~min}$, and then implanted with $0.67 \mathrm{keV} / \mathrm{D}$ ions to the fluence of $1 \times 10^{19} \mathrm{D} / \mathrm{m}^{2}$. The TDS heating rates were varied in the range of $0.15-4 \mathrm{~K} / \mathrm{s}$. Note that all the spectra are plotted not in scale.

Fig. 3 shows the results of TDS measurements performed with different heating rates. For convenience, all the spectra are plotted not in scale. As it can be seen, the second peak corresponding to D release from vacancies clearly shifts towards higher temperatures with increasing heating rate (from $584 \mathrm{~K}$ at $0.15 \mathrm{~K} / \mathrm{s}$ to $649 \mathrm{~K}$ at $4 \mathrm{~K} / \mathrm{s}$ ). However, no clear shift of the first peak was observed. Moreover, the ratios of amplitudes of the two peaks were also different at various heating rates. The origin of these variations is not completely clear. Important factor, possibly, is release of heteronuclear molecules (HD, $\mathrm{HDO}, \mathrm{D}_{2} \mathrm{O}$ ) [40, 41]. For example, the HD contribution decreased with increase of the heating rate (from $40 \%$ at $0.15 \mathrm{~K} / \mathrm{s}$ to $22 \%$ at $4 \mathrm{~K} / \mathrm{s}$ ). The release of $\mathrm{HDO}$ and $\mathrm{D}_{2} \mathrm{O}$ molecules at different heating rates also slightly varied, but, anyway, was much smaller compared to that of $\mathrm{D}_{2}$ and $\mathrm{HD}$ molecules, which indicates the 
presence of only relatively small amount of oxygen on the sample surface [41]. Such variations may be due to adsorption of different amounts of impurities (e.g. hydrogen, water) on the sample surface from the residual gas during TDS performed at different heating rates due to the difference in duration of the measurements (from several minutes at the highest heating rate to more than one hour at the lowest heating rate). One can also notice a contradiction between Fig. 2 and Fig. 3: in Fig. 2 the $400 \mathrm{~K}$ peak is higher than the $600 \mathrm{~K}$ peak at all fluences, whereas in Fig. 3 the $600 \mathrm{~K}$ peak always dominates. These figures were obtained in different experimental campaigns, and the background level of hydrogen was slightly higher in the experiments represented in Fig. 2, which resulted in higher release of HD molecules, especially near $600 \mathrm{~K}$.

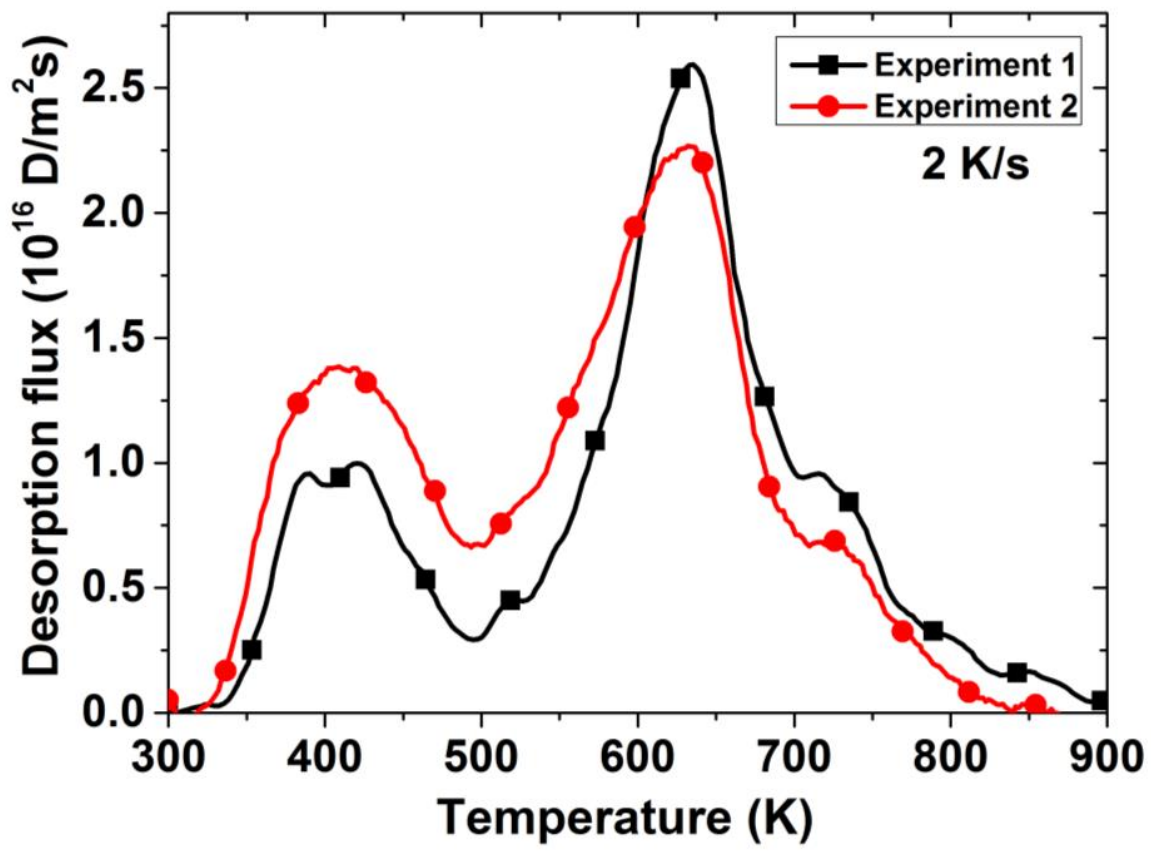

Fig. 4. A comparison of thermal desorption spectra of $\mathrm{D}_{2}$ molecules obtained in different experimental campaigns from recrystallized $\mathrm{W}$ irradiated by $10 \mathrm{keV} / \mathrm{D}$ ions to the fluence of $3 \times 10^{19} \mathrm{D} / \mathrm{m}^{2}$, subsequently annealed at $550 \mathrm{~K}$ for $5 \mathrm{~min}$, and then implanted with $0.67 \mathrm{keV} / \mathrm{D}$ ions to the fluence of $1 \times 10^{19} \mathrm{D} / \mathrm{m}^{2}$. The same sample was used in both experiments. The TDS heating rate was $2 \mathrm{~K} / \mathrm{s}$. 
Fig. 4 shows a comparison of TDS spectra obtained after identical (as technically achievable) implantation conditions for the same sample but in different experimental campaigns. Despite the non-perfect reproducibility of the shapes of the peaks and their relative amplitudes, the positions of the peak near $600 \mathrm{~K}$ are the same (within the uncertainty of the measurements) for both experiments. The amounts of $\mathrm{D}$ released as $\mathrm{D}_{2}$ molecules differ only within $14 \%$. This gives additional confidence about the reliability of the experimental procedure and rather good reproducibility of the results, which is always limited in the case of very low amounts of trapped D [13].

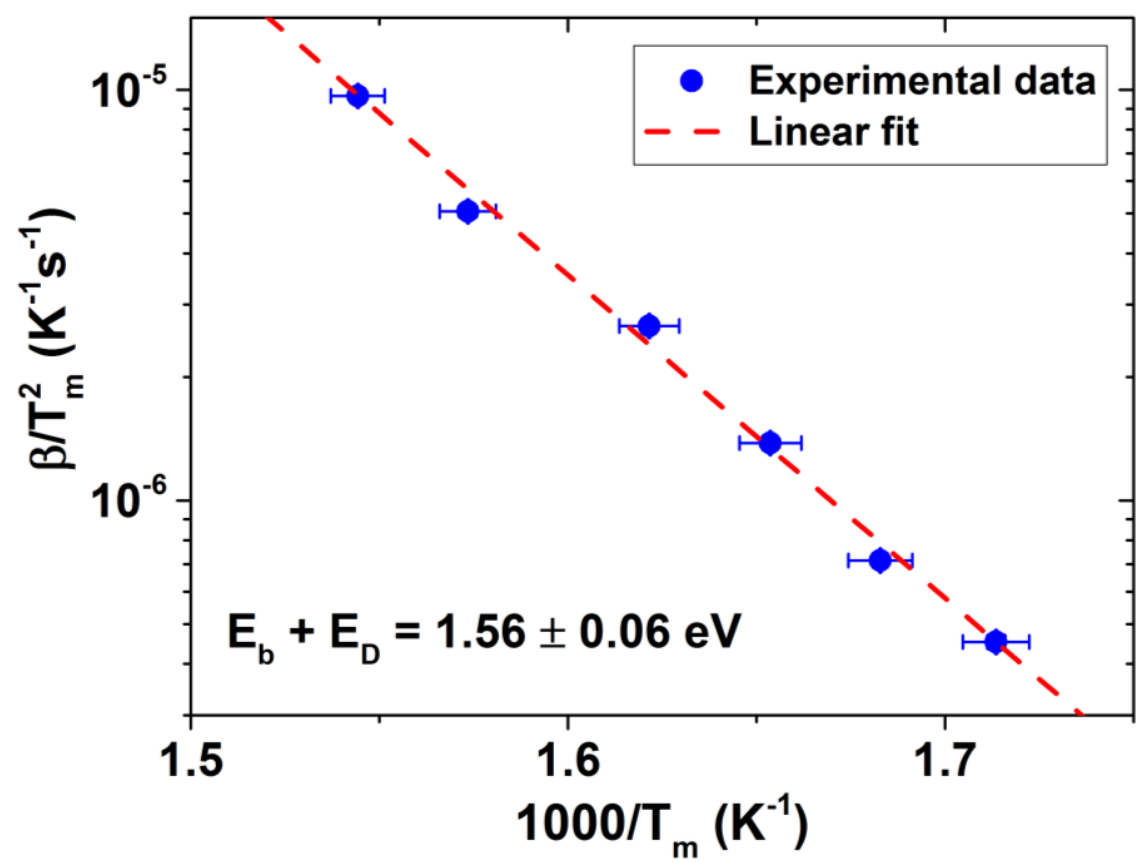

Fig. 5. Semilogarithmic plot of $\beta / T_{\mathrm{m}}{ }^{2}$ versus $1 / T_{\mathrm{m}}$ for the peak corresponding to the $\mathrm{D}$ release from vacancies in $\mathrm{W}$. The best linear fit according to the least squares analysis is also shown.

Fig. 5 shows the semilogarithmic plot $\beta / T_{\mathrm{m}}{ }^{2}$ versus $1 / T_{\mathrm{m}}$ for the peak corresponding to the D release from vacancies. The best linear fit according to the least squares analysis taking into account the experimental uncertainties is also shown. The sum of the $\mathrm{D}$ binding energy $\left(E_{b}\right)$ with vacancies (for the first and probably the second trapped $\mathrm{D}$ atom) and the activation energy for $\mathrm{D}$ 
diffusion $\left(E_{D}\right)$ in $\mathrm{W}$, calculated from the slope of the fit according to Eq. (2), is $E_{b}+E_{D}=$ $1.56 \pm 0.06 \mathrm{eV}$. The fact that all the data points fit well by a straight line indicates that the present results are presumably not influenced by the recombination rate at the temperatures used; otherwise we would observe a crook on the curve discussed in [21].

The value of $E_{b}+E_{D}=1.56 \mathrm{eV}$ is in a good agreement with that obtained by Fransens et. al. [2] $(1.55 \mathrm{eV})$ using the perturbed angular correlation technique, and also close to that obtained from DFT calculations by You et. al. [9] $(1.57 \mathrm{eV}$ both for the first and the second $\mathrm{H}$ atom in a vacancy) and by Heinola et. al. [5] (1.6 eV and $1.57 \mathrm{eV}$ for the first and the second $\mathrm{H}$ atom in a vacancy, respectively). However, it is higher than the commonly accepted value of $1.43 \mathrm{eV}$ obtained by Eleveld and van Veen [3] from simulations of TDS spectra.

\section{Conclusions}

Experiments on thermal desorption of $\mathrm{D}$ from $\mathrm{W}$ were performed in conditions when single vacancies give a well resolved peak. A series of TDS spectra was measured at different heating rates in identical conditions of defect production and D infilling . Experimental data on the shift of the TDS maximum with the heating rate were analysed using the analytical formulas obtained for the condition of a high D-D recombination efficiency at the surface. The functional Arrhenius-like dependence plotted using experimental data was perfectly linear as the analysis predicts. By using this method the sum of the D binding energy with vacancies (for the first and probably the second trapped $\mathrm{D}$ atom) and the activation energy for $\mathrm{D}$ diffusion in $\mathrm{W}\left(E_{b}+E_{D}=\right.$ $1.56 \pm 0.06 \mathrm{eV}$ ) was directly determined without any assumptions and prior knowledge of trap parameters. 


\section{Acknowledgements}

We would like to thank Dr. K. Schmid (IPP, Garching) for SDTrimSP calculations. This work was supported by the Russian Ministry of Education and Science (Contract 14.Y26.31.0008).

\section{References}

[1] J. Roth, K. Schmid, Physica Scripta, T145 (2011) 014031.

[2] J.R. Fransens, M.S.A.E. Keriem, F. Pleiter, Journal of Physics: Condensed Matter, 3 (1991) 9871.

[3] H. Eleveld, A. van Veen, Journal of Nuclear Materials, 191-194, Part A (1992) 433-438.

[4] M. Poon, A.A. Haasz, J.W. Davis, Journal of Nuclear Materials, 374 (2008) 390-402.

[5] K. Heinola, T. Ahlgren, K. Nordlund, J. Keinonen, Physical Review B, 82 (2010) 094102.

[6] D.F. Johnson, E.A. Carter, Journal of Materials Research, 25 (2010) 315-327.

[7] K. Ohsawa, J. Goto, M. Yamakami, M. Yamaguchi, M. Yagi, Physical Review B, 82 (2010) 184117.

[8] Y.-L. Liu, H.-B. Zhou, Y. Zhang, Journal of Alloys and Compounds, 509 (2011) 8277-8282.

[9] Y.-W. You, X.-S. Kong, X.-B. Wu, Y.-C. Xu, Q.F. Fang, J.L. Chen, G.-N. Luo, C.S. Liu, B.C. Pan, Z. Wang, AIP Advances, 3 (2013) 012118.

[10] N. Degtyarenko, A. Pisarev, Physics Procedia, 71 (2015) 30-34.

[11] N. Fernandez, Y. Ferro, D. Kato, Acta Materialia, 94 (2015) 307-318.

[12] A.A. Pisarev, I.D. Voskresensky, S.I. Porfirev, Journal of Nuclear Materials, 313-316 (2003) 604608.

[13] O.V. Ogorodnikova, J. Roth, M. Mayer, Journal of Applied Physics, 103 (2008) 034902.

[14] K. Schmid, V. Rieger, A. Manhard, Journal of Nuclear Materials, 426 (2012) 247-253.

[15] Y.M. Gasparyan, O.V. Ogorodnikova, V.S. Efimov, A. Mednikov, E.D. Marenkov, A.A. Pisarev, S. Markelj, I. Čadež, Journal of Nuclear Materials, 463 (2015) 1013-1016.

[16] J. Guterl, R.D. Smirnov, S.I. Krasheninnikov, M. Zibrov, A.A. Pisarev, Nuclear Fusion, 55 (2015) 093017. 
[17] E.A. Hodille, X. Bonnin, R. Bisson, T. Angot, C.S. Becquart, J.M. Layet, C. Grisolia, Journal of Nuclear Materials, 467, Part 1 (2015) 424-431.

[18] A.A. van Gorkum, E.V. Kornelsen, Vacuum, 31 (1981) 89-98.

[19] E.V. Kornelsen, A.A. van Gorkum, Vacuum, 31 (1981) 99-111.

[20] J. Guterl, R.D. Smirnov, S.I. Krasheninnikov, Journal of Applied Physics, 118 (2015) 043302.

[21] M.S. Zibrov, A.S. Shubina, Y.M. Gasparyan, A.A. Pisarev, Problems of Atomic Science and Technology, ser. Thermonuclear Fusion, 38 No. 1 (2015) 32-41 (in Russian).

[22] G.S. Was, Fundamentals of Radiation Materials Science, Springer Berlin Heidelberg, 2007.

[23] H. Eleveld, A. van Veen, Journal of Nuclear Materials, 212-215, Part B (1994) 1421-1425.

[24] A. Debelle, M.F. Barthe, T. Sauvage, Journal of Nuclear Materials, 376 (2008) 216-221.

[25] H.E. Kissinger, Journal of Research of the National Bureau of Standards, 57 (1956) 217-221.

[26] V.S. Efimov, Yu.M. Gasparyan, A.A. Pisarev, Journal of Surface Investigation. X-ray, Synchrotron and Neutron Techniques, 7 (2013) 472-478.

[27] A.A. Rusinov, Yu.M. Gasparyan, S.F. Perelygin, A.A. Pisarev, S.O. Stepanov, N.N. Trifonov, Instruments and Experimental Techniques, 52 (2009) 871-876.

[28] A. Manhard, M. Balden, S. Elgeti, Practical Metallography, 52 (2015) 437-466.

[29] A. Mutzke, R. Schneider, W. Eckstein, R. Dohmen, SDTrimSP Version 5.00, Report IPP 12/8, MaxPlanck-Institut für Plasmaphysik, Garching, Germany, 2011.

[30] ASTM E521-96(2009)e2, Standard Practice for Neutron Radiation Damage Simulation by ChargedParticle Irradiation, ASTM International, West Conshohocken, PA, 2009, www.astm.org.

[31] M. Zibrov, Y. Gasparyan, S. Ryabtsev, A. Pisarev, Physics Procedia, 71 (2015) 83-87.

[32] A. Rusinov, Y. Gasparyan, N. Trifonov, A. Pisarev, S. Lindig, M. Sakamoto, Journal of Nuclear Materials, 415 (2011) S645-S648.

[33] R. Sakamoto, T. Muroga, N. Yoshida, Journal of Nuclear Materials, 220-222 (1995) 819-822.

[34] G. R. Longhurst, TMAP7 user manual, Idaho National Engineering and Environmental Laboratory, Idaho Falls, Idaho 83415, INEEL/EXT-04-02352 Rev. 2, 2008.

[35] P.W. Tamm, L.D. Schmidt, The Journal of Chemical Physics, 54 (1971) 4775-4787.

[36] A.V. Varava, Vacuum, 44 (1993) 933-934.

[37] A.A. Pisarev, A.V. Varava, S.K. Zhdanov, Journal of Nuclear Materials, 220-222 (1995) 926-929. 
[38] D. Terentyev, V. Dubinko, A. Bakaev, Y. Zayachuk, W.V. Renterghem, P. Grigorev, Nuclear Fusion, 54 (2014) 042004.

[39] S. Ryabtsev, Yu. Gasparyan, M. Zibrov, A. Shubina, A. Pisarev, Deuterium thermal desorption from vacancy clusters in tungsten, Nucl. Instr. Meth. B (2016), http://dx.doi.org/10.1016/j.nimb.2016.04.038. [40] A.A. Pisarev, Y.V. Borisyuk, A.V. Varava, V.N. Tsyplakov, Journal of Nuclear Materials, 258-263, Part 1 (1998) 1138-1142.

[41] K.A. Moshkunov, K. Schmid, M. Mayer, V.A. Kurnaev, Y.M. Gasparyan, Journal of Nuclear Materials, 404 (2010) 174-177. 